\title{
The Influence of Rotor Detuning on Rotor-Stator Interaction Generated Acoustic Response
}

\author{
Scott Sawyer, John M. Feiereisen and Sanford Fleeter \\ School of Mechanical Engineering, Purdue University, West Lafayette, Indiana 47907, USA
}

(Received 10 January 2001; accepted 18 April 2001)

\begin{abstract}
The stator row of a turbomachine is excited by the upstream rotor and responds at multiples of rotor blade pass frequency, resulting in a discrete blade pass frequency tone. Rotor detuning, i.e., unequal circumferential rotor blade spacing, decreases this fundamental tone by breaking the fundamental periodicity of blade passing. However, the stator row responds at additional multiples of rotor shaft pass frequency. This paper is directed at investigating the influence of rotor detuning on discrete frequency noise generation. Complete data were acquired including acoustic mode and stator vane unsteady surface pressure data. Microphones in a circumferential array upstream of the rotor were sampled simultaneously over one rotor revolution, and an ensemble-averaged data set acquired. A dual transform was then utilised to determine the sound pressure amplitude as a function of frequency and spatial mode. The stator acoustic response was also calculated from unsteady stator surface pressure measurements, and the response spectrum was compared with the microphone array data. Rotor detuning is shown to have a significant effect on discrete frequency noise, with an overall reduction in the total sound intensity level for a range of rotor speeds.
\end{abstract}

\section{NOMENCLATURE}

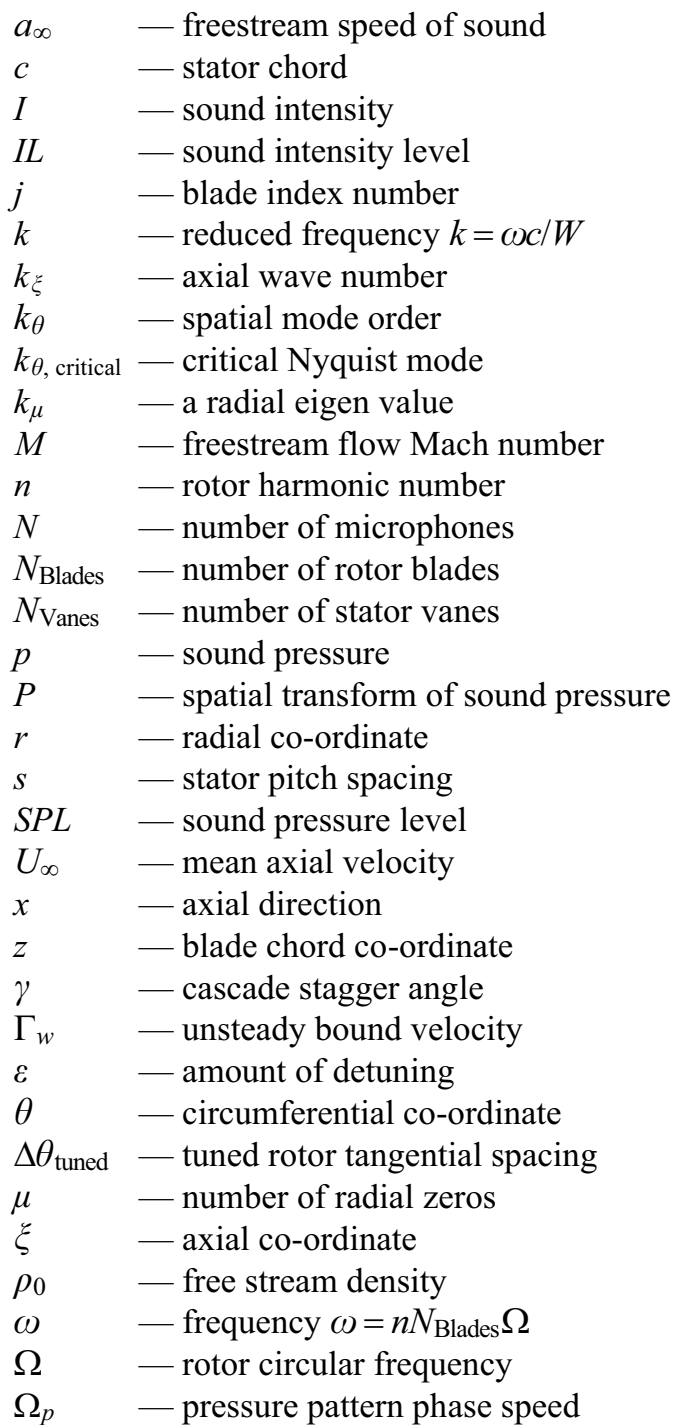

\section{INTRODUCTION}

The primary noise sources in a high bypass turbofan engine are the fan, the low-pressure or booster compressor, and the low-pressure turbine. ${ }^{1}$ Their noise signatures include a broadband noise level, with large spikes or tones at multiples of the blade passing frequency. For subsonic fans, the discrete tones are usually $10-15 \mathrm{~dB}$ above the broadband level.

Current noise control and reduction methods for highbypass turbofan engines usually use a combination of turbomachinery noise source control and suppression approaches. Source control is accomplished by increasing the axial spacing between adjacent blade rows and by selecting blade and vane number combinations to produce "cut-off", whereby the highest-energy acoustic modes decay exponentially with distance along the ducting. Source suppression is achieved with acoustical liners in the fan inlet and exhaust ducts and the core exhaust duct.

The increasing bypass ratios used in turbofan engines involve the use of increased fan diameters. However, nacelle length is normally kept at current bypass ratio size - and is not scaled with diameter. Thus inlet and exhaust duct lengthto-diameters will become smaller. Also, blading becomes larger as fan diameter is increased, and maintaining acoustically desired axial spacing involves a severe weight penalty. Further, the trend toward low blade number, wide-chord fan designs is a further deterrent to maintaining large spacing/ chord ratios. Larger diameters, lower blade numbers, and lower tip speeds all produce lower blade-passing frequencies that require deeper treatment liners to achieve comparable noise suppression. To provide low drag, however, large diameter nacelles must be thin. As a result, current liner treatment designs will provide significantly less noise source suppression.

In summary, higher bypass ratio engines require more noise source control by design - not liner suppression - to even maintain current engine noise levels, let alone reduce

International Journal of Acoustics and Vibration, Vol. 7, No. 1, 2002 (pp 3-10) 